\title{
RETRACTED ARTICLE: Wetland conservation value determination: do individuals pay for conservation improvement in Amirkelayeh International Wetland?
}

\author{
Hamid Amirnejad
}

Received: 2 December 2013/ Accepted: 10 June 2014/Published online: 11 July 2014

(C) Springer Science+Business Media Dordrecht 2014

The Editors in Chief of Wetlands Ecology and Management received a complaint from an alert reader to the effect that the paper 'Wetland conservation value determination: do individuals pay for conservation improvement in Amirkelayeh International Wetland?' by Hamid Amirnejad, published as Online First article in Wetlands Ecology and Management has sections that are plagiarized from an earlier article 'Economic valuation and conservation: Do people vote for better preservation of Shadegan International Wetland?' published by Sara Kaffashi in Biological Conservation (2012, Vol. 150:150-158).
The 'introduction' and 'conclusions' section of the Wetlands Ecology and Management paper contained exactly the same paragraphs as the article published by Sara Kaffashi in 2012. Accordingly, and as per the journal's policy on plagiarism, it has been decided to withdraw the article published by Hamid Amirnejad in Wetlands Ecology and Management and remove the article from the websites of Springer. The Editorial Board takes a serious view of acts of plagiarism in the journal and is committed to take all necessary steps to prevent such acts.

H. Amirnejad ( $\square)$

Department of Agricultural Economics, Sari University of Agricultural and Natural Resources, P.O. 578,

4816118771 Sari, Iran

e-mail: hamidamirnejad@yahoo.com;

h.amirnejad@sanru.ac.ir 